\title{
The curriculum-instruction-assessment triad
}

\author{
Frank Achtenhagen \\ Institute for Human Resource Education and Management, \\ Georg-August-University, Göttingen*
}

\begin{abstract}
International experiences demonstrate that different research traditions lead to different strategies to explain and to develop educational progress. There is a European tradition which focusses for the curriculum and instruction domains on a subject-didactical endeavor, but does not develop comparably an assessment culture. On the other hand we find a mainly US-american dominated tradition (also strongly supported by psychology) which foster the assessment domain under a neglect of content and teaching/learning conditions. By pointing out the mutual dependency of curriculum, instruction and assessment - as it is expressed by the triad metaphor - the necessity is underlined to develop consequently, simultaneously and co-ordinatedly the dimensions of curriculum, instruction and assessment with their interdependency. Necessity and advantages of this approach are worked out.
\end{abstract}

Keywords: curriculum, instruction, assessment, complex teaching-learning environments, web-based assessment

\section{Preliminary remarks}

The title follows a formulation proposed by Pellegrino (2010, p. 4) when he discussed measurement challenges within the agenda «Race to the Top» as a new trial to develop further the educational system of the US. The decisive issue for me in this context is that he is focusing - under an assessment and evaluation perspective - on the importance of curriculum and instruction within an assessment-driven debate. Major reason is that singling out the assessment component and neglecting the importance of curriculum and instruction «can lead to an overall incoherence in the educational enterprise» $(2010$, p. 4). In this context, «curriculum consists of the knowledge and skills in subject matter areas that teachers teach and students are supposed to learn» ... «Instruction refers to methods of teaching and the learning activities used to help students master the content and objectives specified» by the curriculum ... «Assessment is the means used to measure the outcomes of education and the achievement of students with regard to important competencies" (p. 4-5).

* Frank Achtenhagen, Professur für Wirtschaftspädagogik, Georg-August Universität Göttingen, Germany; fachten@uni-goettingen.de 
The assessment component in the triad model has been further developed under recourse to the assessment triangle presented in the US National Academy Report «Knowing What Students Know» (Pellegrino, Chudowsky \& Glaser, 2001) with the corners «cognition», «observation» and «interpretation». «Cognition» in this context «refers to theory, data, and a set of assumptions about how students represent knowledge and develop competence» ... «Observation represents a description or set of specifications for assessment tasks that will elicit illuminating responses» from the learners. «Interpretation», finally, «encompasses all the methods and tools used to reason from fallible observations. It expresses how the observations derived from a set of assessment tasks constitute evidence about the knowledge and skills being assessed» (p. 7).

Whereas the «assessment triangle» is fully concentrating on the assessment business, the triad is highlighting - at least formally - the necessity to treat curriculum and instruction not only as pure suppliers for assessment tasks but as areas which are also of decisive importance for the success of teaching and learning processes.

This development is to be welcomed as one had to observe in the past that a majority of psychologists underestimated the importance of curriculum and instruction - what does not wonder as the content dimension of, for example, the PISA studies was that of the 8th or 9th grade - and, therefore, no problem for the assessment specialists who, normally, attended the 12th or in Germany the 13th grade.

That the discussion about the importance of curriculum and instruction - in the context of the assessment debate - is gaining an increasing attention depends upon an interesting phenomenon: The models of competence measurement, as e. g. Wilson's approach (2005), which also heavily influenced the methodology of the international large-scale assessments set a severe condition: that items can be developed and organized with regard to competence measurement along a linear structure. Wilson's construct maps as one of four building blocks of competence measurement are a convincing example. But the problem is that this condition is very hard to be verified. Weber could demonstrate by her heuristic model of intercultural learning that it is principally possible to develop a linear and hierarchically structured construct map for intercultural learning and that it is possible to prove it by Item Response Theory (Weber, 2009; Weber \& Hofmuth, 2012) (Figure 1). Remarkable is that the order of the items within the Wright Map was identical for different test processes. One prerequisite that she could come to this result is the use of skill hierarchies, following a proposal of van Merrienboer \& Kirschner (2007). 
Figure 1: Construct map for intercultural team competence

Direction of increasing
intercultural competence
Degree of cognitive intercultural actions
(5) Questioning own frame of reference
$\begin{aligned} & \text { (4) Working out a commonly shared } \\ & \text { understanding and common goals }\end{aligned}$
$\begin{aligned} & \text { (3) Inclusion of the social context } \\ & \text { (5) Reflection and questionning of own orientation } \\ & \text { and values system } \\ & \text { cooperation; development of shared perspectives } \\ & \text { (2) Short term pragmatic problem solving } \\ & \text { refering to own perspective } \\ & \text { other as he/she did? Specification of relationships; } \\ & \text { classifying the problem within a broader context } \\ & \text { (1) Self-reflection } \\ & \text { (2) Mechanisms and behavior of how to escape } \\ & \text { quickly without problems from the situation }\end{aligned}$
(1) Identifying own behavior
intercultural competence

Source: Weber, 2005, 2007, in accordance with Ting-Toomey, 1999; Wilson, 2005

In a project as part of the preparation of a large-scale assessment for vocational education and training Winther and Achtenhagen had difficulties to formulate a corresponding one-dimensional linear model for business processes and decided, therefore, to work with three parallel construct maps and to define thereby the structure of tasks and items (Achtenhagen \& Winther, 2009; Winther, 2010). The development and the construction of adequate construct maps is the decisive point for relating curriculum, instruction and assessment stringently to each other - especially if competence measurement follows exclusively the item response theory approach.

In the following the curriculum-instruction-assessment triad is discussed point for point under a subject-didactical perspective in the fields of business administration with regard to the development of competencies which are necessary to master demands in varying complex occupational situations with different distinctness of challenges. This more general discussion of major aspects of the field includes also questions of entrepreneurship education as «competencies can be conceptualized as complex ability constructs that are closely related to performance in real-life situations» (Hartig, Klieme \& Leutner, 2008, p. v) - in our case occupational situations in the fields of business and commerce.

\section{Curriculum}

The experts in the broad fields of assessment and evaluation accept more and more for their research the importance of the goal and content dimensions of teaching and learning - the case of subject didactics. 
Figure 2: Subject didactic and assessment in different countries and disciplines

Didactical reasoning in Germany

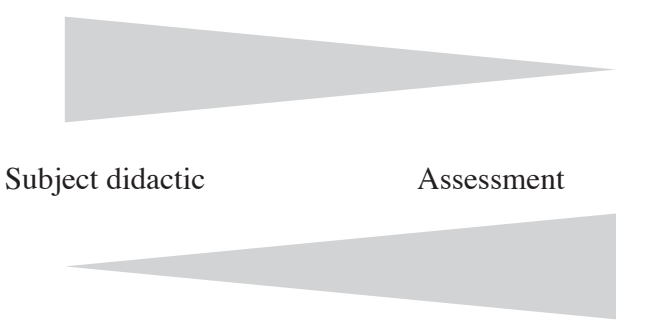

Didactical reasoning in the US (and in psychology)

There is a long European tradition with the topic subject didactic - but also with a neglect of assessment. On the contrary, the majority of researchers in the US followed more the assessment track; one can say that they became aware of subject didactic questions by Shulman's handbook article of 1986 when he focused on the importance of content knowledge and pedagogical content knowledge for effective teaching and learning. But it took nearly 25 years until psychologists accepted this view on teaching and learning processes - but without consequently following it. One interpretation of this actual attention on subject didactic is that it is a politically motivated one: It is more and more accepted for all educational programs in the US like «No Child Left Behind» or «Race to the Top» that these programs cannot be effective without taking into account the content dimension. Higher order abilities cannot be adequately developed without curricular input. To hop the fence to reasoning, critical thinking, problem solving etc. without a thorough treatment of the different content dimensions does not lead to fulfil the objectives of schools, VET or universities. But the assessment specialists try still to keep staying with their traditional approaches. The new idea now is, for example, to force goals and content under the yoke of measurement models. The actual slogan to unify the manifold interests is «learning progression» within recent political programs like «Race to the Top» (Pellegrino, 2010; Corcoran, Mosher \& Rogat, 2009; Daro, Mosher \& Corcoran, 2011). By hoping to identify optimal «learning trajectories» the means shall be given to structure the curriculum, to optimize the instructional processes as well as to make use of, for example, modified IRT models. The terms «learning progression» or «learning trajectory» express a latent political and social hope that educational policy advances into a controllable and manageable direction of greater success of schooling with regard to economic development of the country and also better social chances for all. And also: that the single steps during the progression process follow the right trajectory what could also be stringently controlled.

There are, at the moment, big projects given to foster learning progression and learning trajectories especially in the fields of science and mathematics. Under the 
aspects of curricular research one might have some doubts whether these goals can be reached by the proposed approaches and measures. This is also demonstrated counterfactually by the examples in the appendices of these reports. Correspondingly, on the other side the measurement specialists try to develop new item types as, for example, ordered multiple-choice items and like that (cf. Briggs, Alonzo, Schwab et al., 2006; Briggs \& Alonzo, in press). Shavelson and Kurpuis (in press) had been invited to discuss the «evidence-based approach to educational reform» proposed by Corcoran, Mosher \& Rogat (2009) regarding «learning progression in science». They criticized the approach above all for its simplistic assumptions of linearity and hierarchical structure of objectives and content by pointing out the thesis that the curriculum in all subjects consists of «pieces of knowledge» which makes it nearly impossible to generate an overall linear model of learning progression. Shavelson and Kurpuis postulate that one can identify at least two different approaches - that means: two lines or two trajectories to structure the goal and content dimensions: the curriculum and instruction road as well as the cognition and instruction road, the first starting with a logical analysis of curriculum, the second with a psychological analysis of cognition.

The research question is whether these two approaches - or at least one of them might lead to linear models by which the item development for assessment can be fed. Shavelson and Kurpuis relate the trajectory approach to the ancient myth of Prokrustes who brought all travellers who met him into the right shape for his bed: by cutting the legs if the travellers were too long or by breaking apart and enlarging the backbone if they were too short. In other words: the neglect of the interplay of curriculum and cognition for assessment purposes leads with high probability to a fixation of the content structure and/or a very formal adaptation of the ability and difficulty structures to the fits of the models of competence measurement and not as much to a valid and sense-making description of competencies. ${ }^{1}$

Krajcik (in press) as one activist of the learning progression or learning trajectory movement in science discusses the critic of Shavelson and Kurpuis: He, firstly, states that the idea of learning progression might serve as a positive motto for educational policy: progression stands for development of educational means. But he is also warning that this concept might be converted into a slogan comparable to that of «misconception» where the fundamental idea was abused by many inferior studies which have over time hidden the view on the development of learning itself. Krajcik proposes to support the concept of learning progression - which is not seen by him as a linear model - by the introduction of particles - as he says - which shall build foci within the whole curricular structure and can been used as starting points for composing a network structure of goals and content. This idea is comparable to that of complex teaching-learning environments which shall be introduced later, but it is

1 Interesting is that the authors of the 2009 report on learning progression within science did not mention this critic in their connected 2011 report on learning trajectories within mathematics although Shavelson was explicitly invited to comment on the 2009 report - a nice example of «collegial» assessment. 
still an idea as the curricular and instructional anchors are not given yet. The major point why Krajcik is failing to support the learning progression and learning trajectory movement is that he is neglecting the curriculum-instruction-assessment triad with its corresponding complexity as he does not take into account sufficiently the curricular and instructional dimensions (p. 10). His answer and slogan is the cognition-curriculum-instruction superhighway instead of the two roads presented by Shavelson and Kurpuis. It remains unclear through which suburban gardens such superhighway shall be built and how the necessary interconnection of cognition, curriculum and instruction should be operationalized - especially with regard to the formulation of construct maps.

As mentioned above, construct maps as one of the four building blocks of item construction according to Wilson (2005) are one trial to define ways through the whole mountain of goals and content which can be or are related to a certain subject or occupational area within educational or economic institutions that firms under the heading «concept map» and out of which the curriculum is formed (cf. Figure 3 ).

Figure 3: Elements of subject didactic and assessment

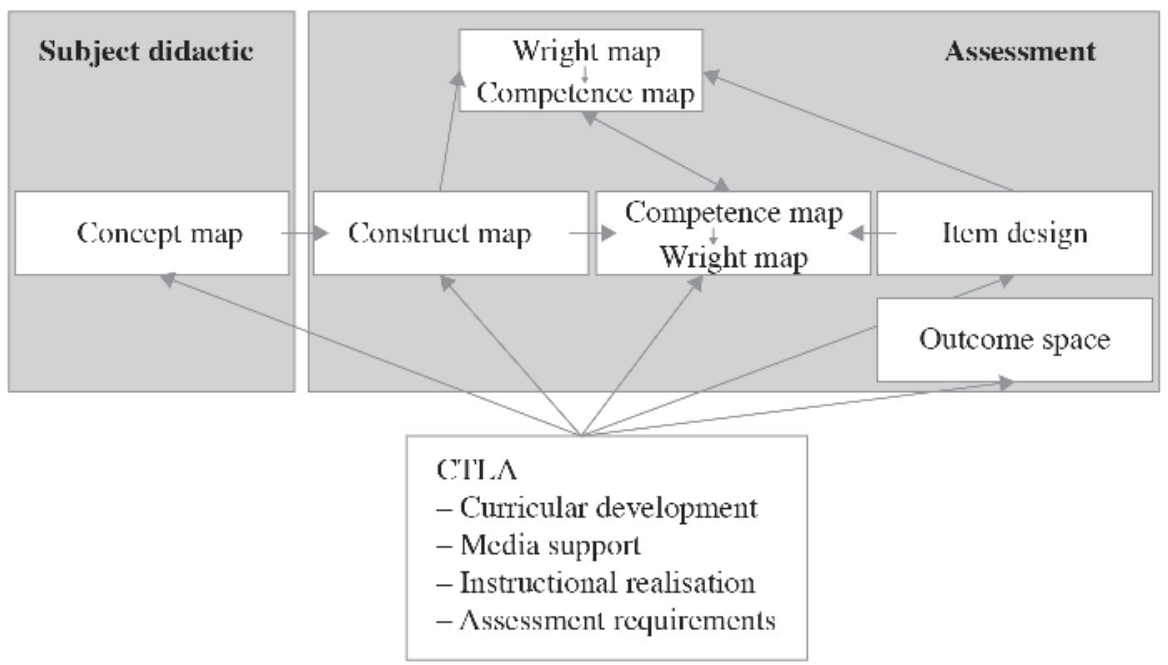

The decisive point is to formulate a construct map in a way that it mirrors important aspects of the curriculum. The theory of didactic and that of different subject didactics is over the centuries full of recommendations of which categories should be used to structure goals and content - for example, are specific goal and content components important for coping with the past, the presence or the future of youth and young adults, or: how close are they to the needs of the workplace?

When Winther and Achtenhagen started in 2008 to develop items for competence measurement in the fields of business administration they saw also these difficulties 
(Winther \& Achtenhagen, 2009). They tried to formulate construct maps taking into account subject-didactical approaches in the fields of business education and training. They refered to that of complex teaching-learning environments (CTLA) as representation of a concept map in this field (cf. Achtenhagen \& John, 1992; Achtenhagen, Tramm, Preiß et al., 1992; Achtenhagen, 2002, 2003) and came to the decision that one needs at least parallelly three construct maps - or three dimensions of a construct map - to relate the concept map adequately to the processes of item design in order to cover the challenges of occupational situations with their complexity, changes and differing demands (cf. Achtenhagen \& Winther, 2009; Winther, 2010, p. 235) (Table 1).

Table 1: Construct map with three dimensions

\begin{tabular}{llll}
\hline Level & Functional modeling & Complexity of context & Cognitive taxonomization \\
\hline 4 & $\begin{array}{l}\text { Excellent functional } \\
\text { modeling }\end{array}$ & Scientific procedures & Applying \\
3 & Correct functional modeling & Reconstruction of theories & Analyzing and validating \\
2 & Partial functional modeling & Coherence of content units & $\begin{array}{l}\text { Understanding and } \\
\text { elaborating }\end{array}$ \\
1 & Incorrect & Isolated units & Reproducing \\
\hline
\end{tabular}

The conclusion was to follow the curriculum and instruction road by a construct map which represents the different complexity of context and necessary knowledge and also to follow the cognition and instruction road by defining a construct map based upon a cognitive taxonomy as that of Marzano \& Kendall (2007). But there is also the necessity of developing a third dimension of the construct map which is called the modelling road of curriculum and instruction. What is meant by this? The necessity resulted from the needs of an adequate and authentic construction of tasks and test items which validly and reliably represent challenges of occupational situations (cf. also Achtenhagen \& Weber, 2003). «Modeling» here refers to the cognitive and knowledge processes necessary to understand fully the specific occupational situation and its demands. One example: if our firm cannot deliver in time and the task for the employee is to write a corresponding letter to the client, the testee should have the competence to model the decisive conditions of the situation that means for example not only to communicate the delay - what is surely a necessary step -, but also to reflect the consequences of this fact for the client (whose production might be stopped if we do not deliver in time), for the firm-client- relationship and its further development and also for the firm image - and, therefore, to formulate the letter correspondingly exactly and politely feeling responsible for treating this situation adequately. By this third dimension we tried to do justice to the difference of competence measurement for mastering occupational situations compared to the measurement of school tasks in e. g. science or mathematics. 
Another point to structure the goal and content dimension is to use scientific theories about the corresponding fields of interest. For the area of business and commerce we followed an approach as it is proposed by the Management Model of St. Gall which postulates a systemic, networklike structure of business processes with central nodes and subnets (cf. Dubs, Euler, Rüegg-Stürm et al., 2004). This approach corresponds to what Shavelson and Kurpuis call «pieces of knowledge». Entrepreneurship education also copes with such network structure as the different modules like marketing, financing, cost controlling etc. have to be consequently interconnected. The major task for the corresponding business planning courses is given by the fact that the business plan has to represent the network structure showing intended main effects and also possible unintended side effects - and the information for the different necessary subnets has to be brought together - for example - by corresponding teamwork. This interplay of hard skills and soft skills will be presented especially by Weber and Funke (this issue of ERVET). The modelling dimension wins especially importance by following the «sense of failure/sense of success»-approach of Oser and Volery (this issue of ERVET) with its cognitive and emotional structures.

In any case, this goal and content structure cannot be easily linearized on the curricular level. The only chance seems to be to lay through this information pattern well founded tracks - the construct maps, where only in selected cases one singular, one-dimensional construct map might help describing and explaining the structure of competencies.

With the conviction that at least for the business domain - and, therefore, also for entrepreneurship education - one should start out with from the fact that objectives and content follow a systemic, network-like structure - which supports the assumption of coping with pieces of knowledge instead of linear hierarchical structures. That was one reason that Achtenhagen proposed - starting in 1985 - to ground the subject didactic in the fields of business and economy on the concept of «complex teaching-learning environments» - whereby these environments step by step were represented by computer- and web-based virtual enterprises. One example shall visualize the construction of the underlying goal and content structure for the initial lessons with such an environment - here a business game (cf. Preiss, 1994, p. 255) (Figure 4). 
Figure 4: Network structure of a complex teaching-learning environment for the first year of instruction in the fields of business and commerce

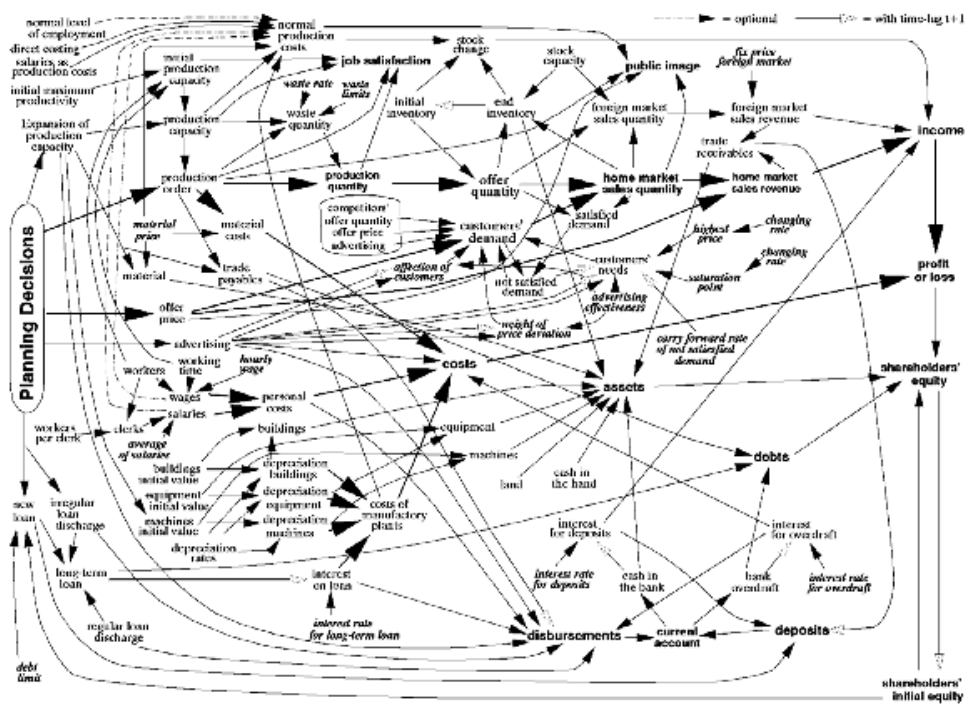

The idea of complex teaching-learning environments is comparable to that of the Jasper Woodbury video series developed independently in the US for mathematic instruction for 5th and 6th graders by the Cognition and Technology Group at Vanderbilt (1997). The situation-specific presentation of networked tasks - for a solution as for example bringing home a ship without lights at daylight it is necessary to solve in advance about 14 subtasks and relate the results to each other and to the final overall solution - shall stimulate cognitive as well as motivational and emotional efforts to learn and to avoid generating inert knowledge or amnesia and phantasia (cf. Shulman, 1999), that means knowledge which cannot be used, which is soon forgotten or leads to completely wrong consequences for memory and actions. ${ }^{2}$

\section{Instruction}

Complex teaching-learning environments need a corresponding treatment within the instructional processes. The attribute «teaching-learning» refers to the fact that the adequate handling of teaching-learning environments urges the support by the teacher or instructor. They are not instructional modes for lonely wolves where teachers let the learners do the tasks on their own. The decisive point with the presentation of complex cases and tasks is that the underlying theoretical assumptions have to be

2 It is interesting that the 2011 report on learning trajectories in mathematics does not go back to this approach. One does not find any quotation although it has been a huge project in school mathematics which also influenced the reports «How People Learn» (Bransford, Brown \& Cocking, 2000) and «Knowing What Students Know» (Pellegrino, Chudosky \& Glaser, 2001). 
systematized by the instructional processes (cf. Reetz \& Tramm, 2000). That is the central message by the development and introduction of teaching-learning environments with the fight against inert knowledge, amnesia and phantasia: the permanent balance between cases presented by the environment and their systematization within instruction. Only if one tries to systematize with regard to the different «pieces of knowledge» the development of deeper understanding can be fostered. And this is the case if the instruction works through well defined parts of the net: demonstrating the importance, making clear the interrelationship of the elements and connections of these nets and also binding subnets to other subnets until the whole structure is understood - and the pieces of knowledge are integrated into a comprehensive structure. This level, then, can be interpreted as expert level - if one follows the noviceexpert schema of knowledge and action comprehension.

Figure 5: Progress in working with a complex teaching-learning environment
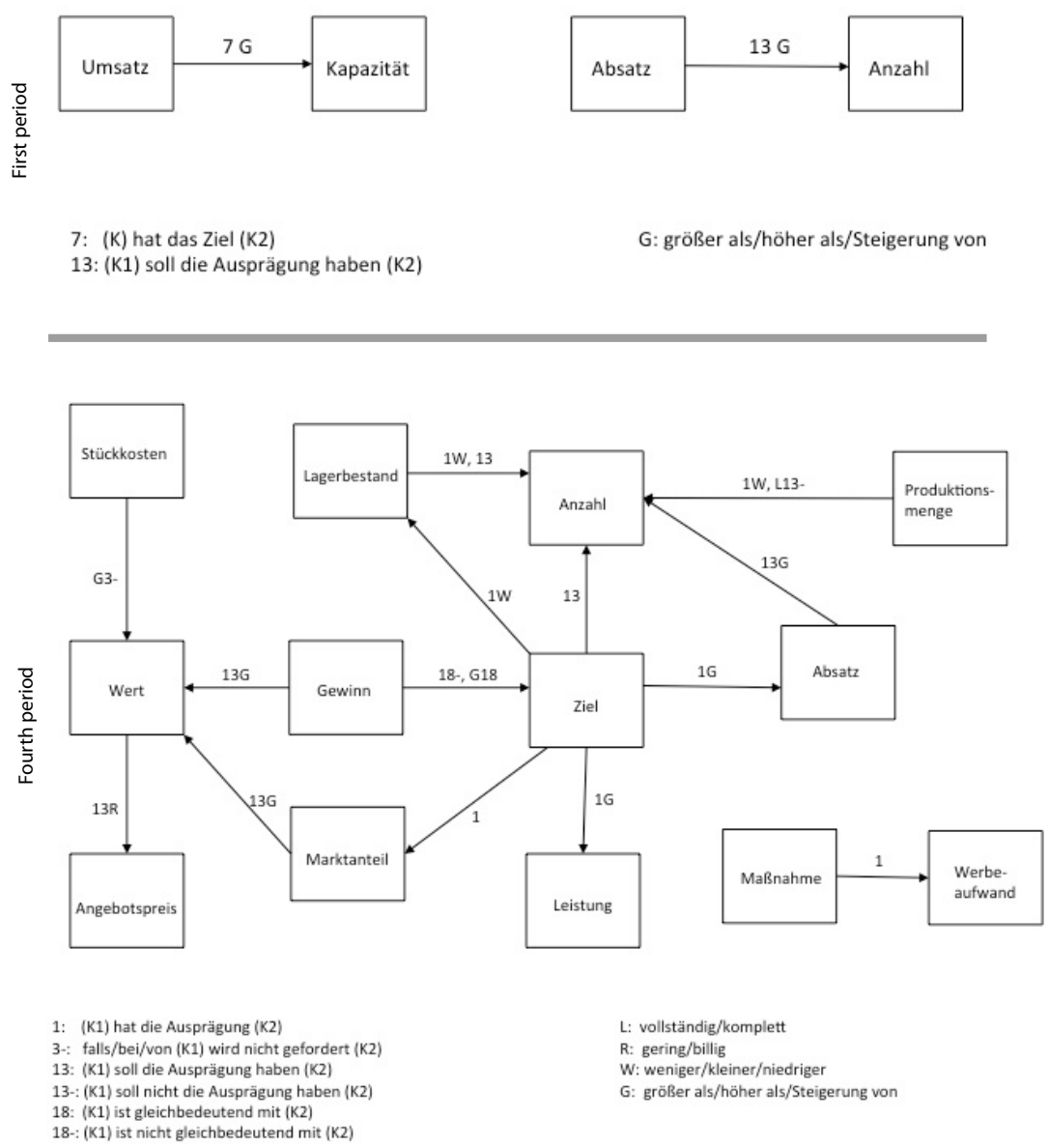
Figure 5 demonstrates the development of group discussions over different periods of a simulation game: The upper row visualizes the discussion within the first period where elements of the net are treated more isolatedly. The subset below shows the discussion in the fourth period. The learners are able to reconstruct larger parts of the network structure (cf. Fürstenau, 1994, p. 174).

If one tries to visualize the entrepreneurial task presented by Weber and Funke (this volume) where an ongoing entrepreneur plans to found a high quality salad delivery service for conscious ladies at high standard service offices, another decisive argument against the assumption of an overall linear and hierarchical goal and content structure within the curriculum is given (Figure 6).

Figure 6: Selected entrepreneurial components for a salad delivery service

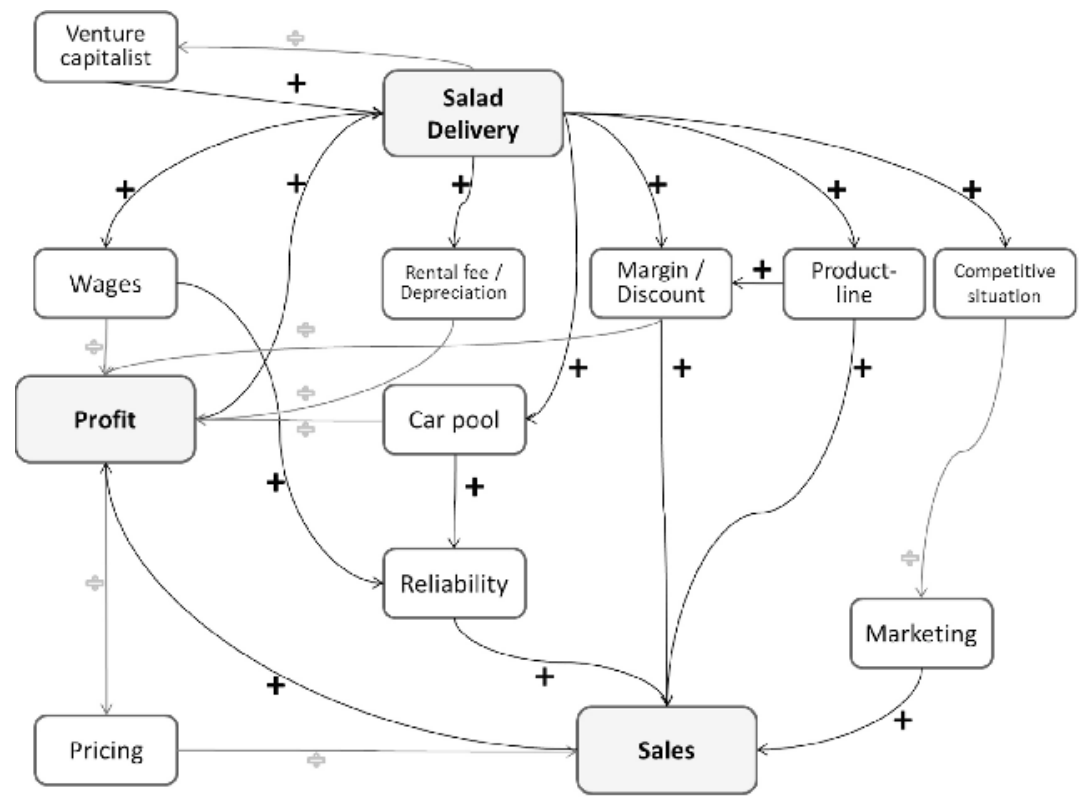

Figure 6 shows a very simplified structure of interdependent business processes which influence each other positively or negatively: sales influence profit positively, margins/discount do this negatively, etc. A business plan has to mirror these influences. By the instruction within such course it might be one possible step to design such map - on the basis of a presented complex teaching-learning environment. With regard to the underlying assumption of «pieces of knowledge» it is possible to focus on different perspectives of this net: One can, for example, treat separatedly the financial and cost accounting perspectives focusing on financial payments etc. or on the calculation for the offered range of salads in comparison to the prices of the competitors. Related to the construction of the curriculum it does mean that business 
processes can be separated under aspects of logistics (productivity), values, binding of capital (rentability) or ability to pay (liquidity) (cf. Achtenhagen, Tramm, et al., 1992; Achtenhagen \& John, 1992). But the important fact is that these different tasks and sub-tasks as cases have to be sequently - and consequently - led to procedures of systematization.

Business planning as a systemic network-like process needs to be elaborated with regard to its very complex starting point and its very complicated details which have to be brought back into a summarizing structure which demonstrates the manifold interdependencies. The breadth and depth of the tasks urge information search, team work and networking. The tasks can only be solved by an integrated use of hard skills and soft skills.

Complex teaching-learning environments need a corresponding treatment within the instructional processes. This depends upon the differences within the work tasks as central part of the occupational situations which have to be mastered by competent entrepreneurs, by intrapreneurs or by employees. The difficulties to assess competencies adequately with regard to founding situations and the generation of a business plan or to given occupational situations are caused by the conditions of work tasks and the specific occupational affordances. We can differentiate work tasks by different specific challenges but also relate them to challenges for entrepreneurship education:

- Work tasks may cover a rich and varied content. For entrepreneurship education one can refer to problems of market analyses: What is the taste of secretaries in high-status offices with regard to their lunch?

- Work tasks may include a large number of variables with different degrees of embedded transparency: Which money limit for salad as daily lunch is given?

- Work tasks may comprise a network with many interrelationships: How to define the space for delivery? Which personnel and traffic equipment is necessary to cover the space?

- Work tasks vary over time in a non-linear manner: Is the wish to get salad everyday stable over time?

- Many work tasks are polytelic - that means combined with intended main and unintended side effects: How does the salad delivery operate with regard to speed, punctuality, reliability, personal costs, transportation and parking space?

These different work tasks need instructional preparation for enabling the mastering of the workplace demands. With regard to the complexity of the goals and content also a variety of instructional measures is urged which have to be supported by the corresponding curricular components. In this case:

- general introduction into the complex task by an anchor video;

- lectures;

- tutorials; 
- e-learning;

- practice introduction (by a real entrepreneur) and professional coaching.

All these instructional efforts have to be related to the curricular input, which depends on the goals of the course: For business planning one has to define new tasks and therefore to fix possible and necessary task hierarchies. For business processes as it is the case for commercial apprenticeships web-based material has been provided. In the business planning course the instructional means are related to hard skills as well as to soft skills. The necessary information with regard to market analyses, marketing or financing is won by team work and has to be searched by team members and adequately presented within the team and later, then, to a bank or a venture capitalist. As the tasks are differing by their level of mastering, different task hierarchies have been developed according to Van Merrienboer \& Kirschner (2007).

By that procedure the solutions are worked out with regard to authentic occupational situations (cf. Achtenhagen \& Weber, 2003) under use of different kinds of knowledge and by using different kinds of actions and activities. All this can be sufficiently described by the three-dimensional construct map mentioned above which helps stabilizing the curriculum-instruction-assessment triad.

\section{Assessment}

The 3rd facet of the triad is assessment. Whereas curriculum and instruction try to develop, enlarge and stabilize competencies, assessment gets the task to measure whether these goals are reached. The central thesis is that curriculum, instruction and assessment should strongly and stringently be related to each other as triad - with the intention to get the same levels of complexity for all elements of the triad. This means that the assessment tasks and test items should mirror the complexity of curriculum and instruction which for their part should mirror the variation and complexity of occupational situations with their differing challenges. Tasks and test items should therefore get a structure which is comparable to that of a complex teaching-learning environment. This is not a futile assumption of hope, but given by actual practice. Shavelson (2010) demonstrates for the Collegiate Learning Assessment approach (CLA) how differentiatedly tasks are formulated and presented, that test items can be developed which allow judgments about and scoring of reasoning, critical thinking, problem solving or written communication of the testees. The German «Aufgabenstelle für kaufmännische Abschluss- und Zwischenprüfungen» - an institution which organizes for Chambers of Industry and Commerce the examinations of commercial apprentices - is developing complex tasks to be solved which comprehend up to 20 pages of written text to model the business situations and processes which have to be treated by the examinees (cf. Winther, 2011). It comes close that the presentation of authentic business situations as the basis of presenting tasks and test items should be computer-based or web-based. But that, naturally, causes a lot of costs and endeavour (cf. Achtenhagen \& Winther, 2009; Winther, 2010). 
Between assessment procedures for entrepreneurship education and the mastering of business processes within commercial apprenticeships an important difference exists: Within commercial apprenticeships business processes are given and have to be treated and the resulting tasks to be solved. Here, a computer- or web-based test design is helpful with regard to an authentic presentation of the tasks and test items.

For entrepreneurship education the facts are more complicated: There is a starting point with regard to the net structure of the founding process and the major goal and content fields. But: the necessary information is not given or well documented as in the usual cases of business processes; it has to be worked out: Going back to the example of the salad delivery project: It is necessary for developing the business plan to find out the number and quality of potential competitors or - as a second task - the lunch behaviour, the weight watching behaviour and the willingness to spend money for a special salad lunch of secretaries between 30 and 40 years in lawyers' or other service offices within the potential and manageable delivery space. All these and other necessary information have to be put together in a business plan which can and has to be presented to a bank and/or other venture capitalists. And the kind of presentation and persuasion is also a decisive prerequisite for success. The combination and interaction of hard skills - the breadth and depth of corresponding knowledge - and of soft skills as information search, rhetoric, presentation, emotional stability, team work and networking is urged by the business planning processes and their realization. The product business plan and the escorting soft skills form the basis for assessment within the fields of entrepreneurship education. By the formulation of corresponding construct maps it might be possible to use test procedures out of the Rasch family. But also the proposals of CLA might be very adequate for the measurement of competence.

Another question arises: Are we able to convert results of CLA - or a comparable modelling of competencies - into scores which can be used by IRT procedures or by constructing corresponding vectors of test scores for each testee to apply for example Bayesian network procedures? An example from medical education visualizes desirable answer patterns where groups of tasks ( $\mathrm{L}=$ low; $\mathrm{M}=$ medium; $\mathrm{H}=$ high) and learners can be separated (Zhang \& Lu, 2011):

Table 2: Example for selecting tasks and learners by using Bayesian network techniques

\begin{tabular}{lccccc}
\hline Group & CF trajectory & $\begin{array}{c}\text { Recognizing } \\
\text { information }\end{array}$ & $\begin{array}{c}\text { Deep } \\
\text { cognition }\end{array}$ & $\begin{array}{c}\text { Cognitive } \\
\text { action }\end{array}$ & $\begin{array}{c}\text { Subject } \\
\text { number }\end{array}$ \\
\hline A & L & L & L & L & $1,9,12$ \\
B & M & L & L & L & $5,6,7,10,11$ \\
C & M & L & M & L & $4,8,13$ \\
D & M & M & M & L & 2 \\
E & M & M & H & L & 3 \\
\hline
\end{tabular}


A major question remains: How are the influences of a priori probabilities under control? - It might be helpful for competence measurement for business planning to check proposals as they have been modeled for business processes: as parts of the official curricula of commercial apprenticeships. Winther and Achtenhagen (2009; Achtenhagen \& Winther, 2009; Winther, 2010) developed tasks and test items which are modeled according to the approach of complex teaching-learning environments. Tasks and test items can be related to business processes as they are found in real enterprises. One example: the underlying virtual enterprise ALUSIM was modeled according to a real enterprise which produces aluminium products like boxes for Nivea or cans for Coca Cola. Information was won by observations of processes in the real firm, talks with employees, instructors, heads of departments, members of the work council, but also with teachers of commercial schools. Goal was to develop exemplarily tasks and test items as they could be principally used for a large-scale assessment in vocational education and training. ${ }^{3}$ Processes for the departments sales, purchase and production planning have been selected, but also background information for the whole enterprise, e. g. its history, its profit, its cost structure and balances, have been provided.

Figure 7: User interface of the assessment tool ALUSIM

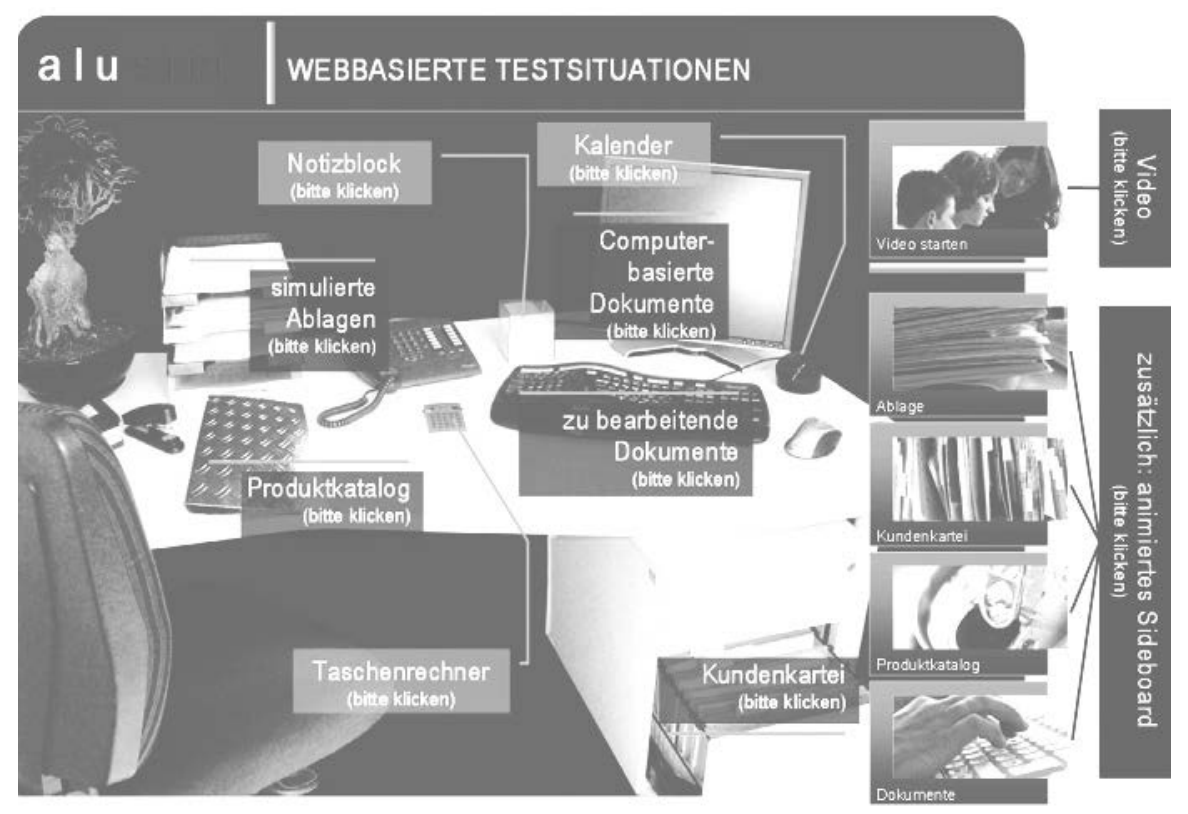

3 The project was granted by the German Federal Ministry of Education and Research: K 350600. 
Figure 8: Order by fax (as task example)

\section{FACT Dosiertechnik GmbH}

01099 Dresden

Königsbrücker Str. 103

E-Mail: kontakt@fact-dosier.de

FACT Dosieftechnik GmbH, K3̈nigsbridcker Str. 103, 01099 Dresden

\begin{abstract}
ALUSIM GmbH
Herrn Heiner Kolbe

Goethestraße 33

34119 Kassel
\end{abstract}

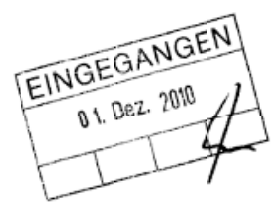

FACT

III

Dosiertechnik

$\mathrm{GmbH}$

Iir Zeeschen, bre Nachricht von

Ko, 01.10 .2010

Unser
Glü

Touktor, Name 0351 geses.

Oatum 2.12 .2010

Bestellung

Sehr geehrter Herr Kolbe,

unter Berücksichtigung Ihrer für uns neuen Konditionen mòchten wir gerne $5.000 \times$

Artikel - Nr. 230330 Aluminiumkartuschen zum nächstmöglichen Liefertermin bestellen.

Mit freundlichen Grüßen

FACT Dosiertechnik GmbH

$x=5$

Margot Glüsing 
Figure 9: ERP scheme (to be filled with the data of the fax order)

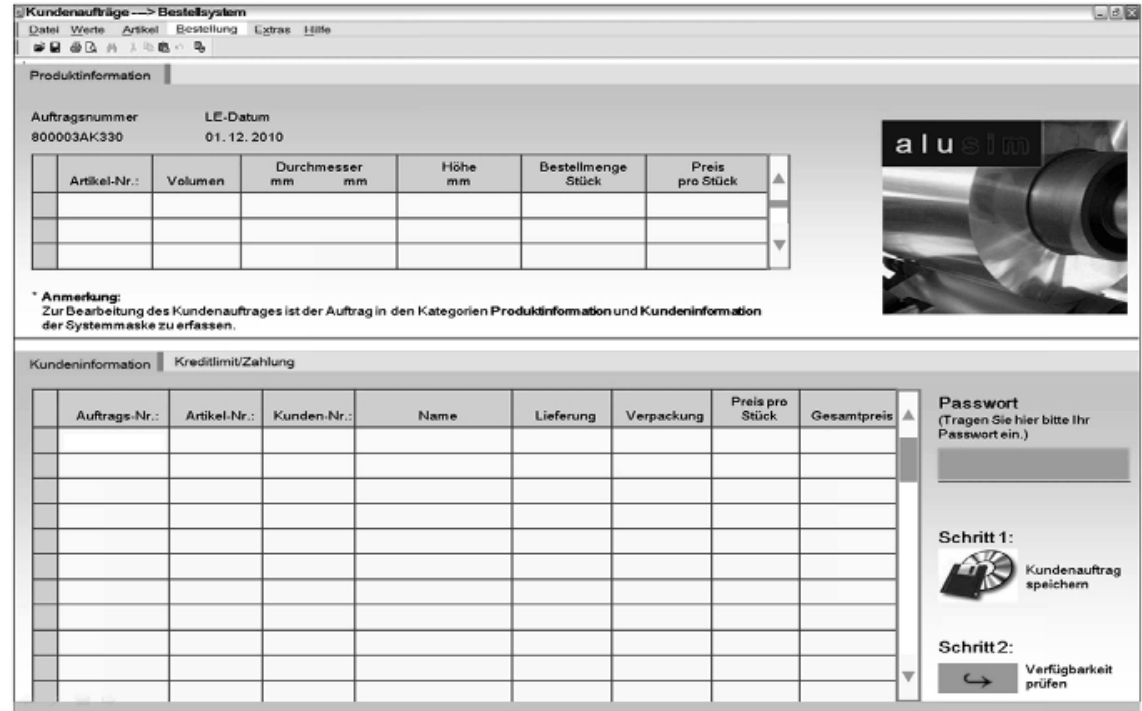

Figure 10: Mail of the production department: no delivery

Kolbe, Heiner

$\begin{array}{ll}\text { Von: } & \text { "Theresa Heinrich“ [heinrich@alusim.de] } \\ \text { Gesendet: } & \text { Mittwoch, 01. Dezember 2010, 17:16 Uhr } \\ \text { An: } & \text { Kolbe, Heiner }\end{array}$

An: $\quad$ Kolbe, Heiner

Auftragsnummer 800003 AK330 konnte vom Versand nicht ausgeführt werden; die geforderte Menge war nicht vorrätig.

Der Auftrag wurde daher von uns in die aktuelle Produktionsplanung eingebucht.

Fertigungssteuerung

ALUSIM GmbH, Werk Kassel

Goethestraße 33

D-34119 Kassel

Direct +49 (0) $561 / 988-45$

Fax: $\quad+49(0) 561 / 988-46$

E-mail: heinrich@alusim.de

ALUSIM GmbH

Sitz: Kassel (HRB 38092)

Geschāftsführung: Dr. Konrad Kluge 
Figure 11: E-mail form for message to the client

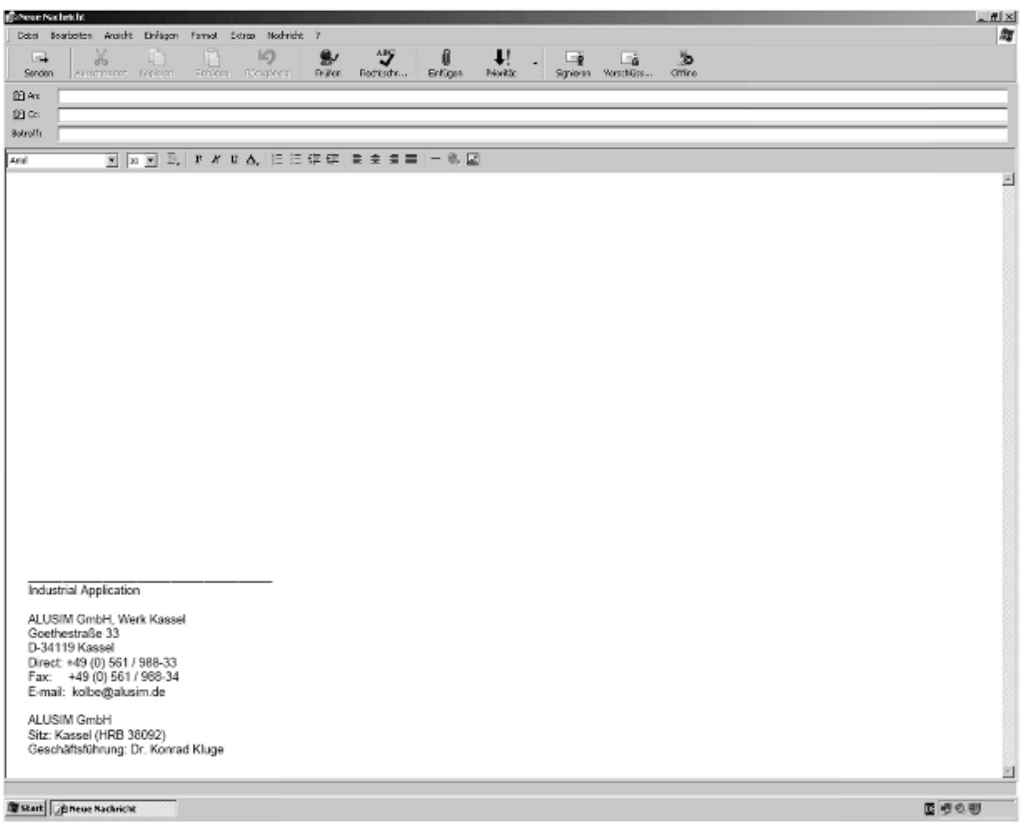

Figure 7 shows the user-interface of the assessment tool. Each work situation is introduced by a video-clip which visualizes an office situation and defines the task to be solved. The video-clips are ordered as sequences; by that a business process can be followed over time: whether it succeeds or whether disturbances have to be managed. Each testee disposes of a desk by which all manipulations of information and actions can be handled. Catalogues with product, client and deliverer information are given. E-mails can be received and sent. The solution of each test item is sent to the web central.

Figures 8 and 9 demonstrate a sequence of work tasks: An order by fax comes in; the information has to be completed and brought into the ERP system. The delivery date has to be sent to the client. Then, Figure 10, a mail from the production department says that the delivery date is not valid anymore. The testee, then, has to develop an e-mail (Figure 11) which communicates the facts, but takes also into account - by its style - the possible consequences for the future firm-client relationship (one modeling aspect of the construct map).

As all tasks and test items represent typical challenges within business situations, the results can be used for measuring the competence of mastering business processes. By working with ConQuest and using the MRCML model (Wu, Adams, Wilson et al., 2007; Adams, Wilson \& Wang, 1997) excellent model fits by only 264 testees and 58 items are given - a fact that can be interpreted as a consequence of the 
subject didactical preparation of the test items by grounding the assessment procedure on complex teaching-learning environments. Another advantage is that the test items also can be used for the introduction into teaching-learning processes about business actions and their adequate handling (cf. the fax example). It is also principally possible to define levels of competence which correspond to the goals set by the German States and the Entrepreneurs and Trade Unions for this specific apprenticeship. We found a nearly linear structure of the test items with regard to the abilities of the testees and the difficulties of the items (cf. Achtenhagen \& Winther, 2009; Winther, 2010).

\section{Concluding remarks}

The examples show competence measurement for the commercial apprenticeship of industrial clerks. The problem arises of how to measure competence in the field of entrepreneurship. Central is hereby the generation of new situations for an enterprise. Shall such an assessment follow a Collegiate Learning Assessment approach how it seems to be adequate for business planning or an IRT approach which seems to function for business processes? Or is it worthwhile to combine IRT and CLA approaches trying also to convert CLA information into IRT models? The questions are related to those of the structure of curriculum and instruction. Accepting the hypothesis that we are coping with varying, complex situations with differing challenges in the occupational fields, one answer seems to be clear: We need the view on the whole curriculum-instruction-assessment triad and should foster its interconnection by the construction of complex teaching-learning environments which lead the instruction and are also adequate for the measurement of competencies to master such arrangements. By that, the thesis of linearity and hierarchy of goals and content does not play the decisive role as the environments combine pieces of knowledge which can be used separately for assessment purposes but be also embedded into more overarching structures. Decisive is the consequent use of relating casuistic and systematization for each piece and the whole to each other. This is the necessary prerequisite for the functioning of the curriculum-instruction-assessment triad. But we have also to promote experts who oversee and master the entire goal and content structure from the curriculum over the instruction to assessment and the way back. These are the two central messages of coping with the curriculum-instruction-assessment triad.

\section{References}

Achtenhagen, F. (2002): Die Unternehmung als komplexes ökonomisches und soziales System. In: F. Achtenhagen (Ed.): Forschungsgeleitete Innovation der kaufmännischen Berufsausbildung - insbesondere am Beispiel des Wirtschaftsgymnasiums. Bielefeld: Bertelsmann

Achtenhagen, F. (2003). Konstruktionsbedingungen für komplexe Lehr-Lern-Arrangements und deren Stellenwert für eine zeitgemäße Wirtschaftsdidaktik. In: F.-J. Kaiser \& H. Kaminski (Eds.): Wirtschaftsdidaktik. Bad Heilbrunn: Klinkhardt

Achtenhagen, F. \& John, E. G. (Eds.) (1992). Mehrdimensionale Lehr-Lern-Arrangements - Innovationen in der kaufmännischen Aus- und Weiterbildung. Wiesbaden: Gabler 
Achtenhagen, F.; Tramm, T.; Preiß, P. et al. (1992). Lernhandeln in komplexen Situationen. Wiesbaden: Gabler

Achtenhagen, F. \& Weber, S. (2003): «Authentizität» in der Gestaltung beruflicher Lernumgebungen. In: A. Bredow, R. Dobischat \& J. Rottmann (Eds.): Berufs- und Wirtschaftspädagogik von A-Z. Baltmannsweiler: Schneider

Achtenhagen, F. \& Winther, E. (2009). Konstruktvalidität von Simulationsaufgaben: Computergestützte Messung berufsfachlicher Kompetenz - am Beispiel der Ausbildung von Industriekaufleuten. Abschlussbericht zur Einreichung beim BMBF. Göttingen: Professur für Wirtschaftspädagogik der Georg-August Universität Göttingen

Adams, R. J.; Wilson, M. \& Wang, W. (1997). The Multidimensional Random Coefficients Multinomial Logit Model. Applied Psychological Measurement, 21, 1-23

Bransford, J. D.; Brown, A. L. \& Cocking, R. R. (Eds.) (2000). How People Learn. Washington, DC: National Academy Press

Briggs, D. C. \& Alonzo, A. C. (2009). The Psychometric Model of Ordered Multiple-Choice Item Responses for Diagnostic Assessment with A Learning Progression. Paper Presented at the Learning Progression in Science Conference, June 2009, Iowa City, IA

Briggs, D. C.; Alonzo, A. C.; Schwab, C. et al. (2006). Diagnostic Assessment With Ordered MultipleChoice Items. Educational Assessment, 11, 33-63

Corcoran, T.; Mosher, F. A. \& Rogat, A. (2009). Learning Progressions in Science. An Evidence-based Approach to Reform. CPRE Research Report \# RR-63. New York: Columbia University

CTGV [Cognition and Technology Group at Vanderbilt] (1997). The Jasper Project: Lessons in curriculum, instruction, assessment, and professionnal development. Mahwah, NJ: Erlbaum

Daro, P.; Mosher, F. A. \& Corcoran, T. (2011). Learning Trajoctories in Mathematics. A Foundation for Standards, Curriculum , Assessment and Instruction. CPRE Research Report \#RR-68. New York: Columbia University

Dubs, R.; Euler, D.; Rüegg-Stürm, J. et al. (2004). Einführung in die Managementlehre, Bd. 1. Bern: Haupt Fürstenau, B. (1994). Komplexes Problemlösen im betriebswirtschaftlichen Unterricht. Wiesbaden: Gabler Hartig, J.; Klieme, E. \& Leutner. D. (Eds.) (2008). Assessment of Competencies in Educational Contexts. Göttingen: Hogrefe

Krajcik, J. S. (2009). The Importance, Cautions and Future of Learning Progression Research - Some Comments on Rich Shavelson's and Amy Kurpius's Reflections on Learning Progressions. In: A. C. Alonzo, A. Wenk Gotwals (Eds.): Learning Progressions in Science: Current Challenges and Future Directions. Rotterdam: Sense

Marzano, R. J. \& Kendall, J. S. (2007). The New Taxonomy of Educational Objectives. 2nd ed. Thousand Oaks, CA: Corwin

Pellegrino, J. W. (2010). The Design of an Assessment System for the Race to the Top: A Learning Sciences Perspective on Issues of Growth and Measurement. Princeton: Educational Testing Service

Pellegrino, J. W.; Chudowsky, N. \& Glaser, R. (Eds.) (2001). Knowing What Students Know - The Science and Design of Educational Assessment. Washington, DC: National Academy Press

Preiss, P. (1994). Schema-based modelling of complex economic situations. In: W. J. Nijhof \& J. N. Streumer (Eds.): Flexibility in training and vocational education. Utrecht: Lemma

Reetz, L. \& Tramm, T. (2000) Lebenslanges Lernen aus der Sicht einer berufspädagogisch und wirtschafts-pädagogisch akzentuierten Curriculumforschung. In: F. Achtenhagen \& W. Lempert (Eds.), Lebenslanges Lernen im Beruf. Seine Grundlegung im Kindes- und Jugendalter. Bd. V. Opladen: Leske+Budrich

Shavelson, R. J. (2009). Reflections on Learning Progressions. Paper Presented at the Learning Progression in Science Conference, June 2009, Iowa City, IA

Shavelson, R. J. (2010). Measuring College Learning Responsibly. Stanford: Stanford University Press

Shavelson, R. J., \& Kurpuis, A. (in press). Reflections on Learning Progressions. Paper Presented at the Learning Progression in Science Conference, June 2009, Iowa City, IA

Shulman, L. S. (1986). Paradigms and Research Programs in the Study of Teaching: A Contemporary Perspective. In: M. C. Wittrock (Ed.), Handbook of Research on Teaching. 3rd ed. New York: MacMillan

Shulman, L. S. (1999). Taking Learning Seriously. Change, 31(4), 11-17 
Van Merriënboer, J. J. G. \& Kirschner, P. A. (2007). Ten steps to complex learning: A systematic approach to four-component instructional design. Mahwah, NJ: Erlbaum

Weber, S. (2009). Kompetenzorientierte Unterrichtsgestaltung. Arbeitspapier. München: Institut für Wirtschaftspädagogik der Ludwig-Maximilians-Universität München

Weber, S. \& Hofmuth, M. (2012). Messung unterschiedlicher Facetten von interkultureller Komeptenz. In: G. Niedermair (Ed.), Kompetenzen entwickeln, messen und bewerten. Linz: Trauner

Wilson, M. (2005). Constructing Measures. Mahwah, NJ: Erlbaum

Winther, E. (2010). Kompetenzmessung in der beruflichen Bildung. Bielefeld: Bertelsmann

Winther, E. (2011). Kompetenzen messen - Zur Notwendigkeit methodologischer und quantitativer Standards im Rahmen beruflicher Kompetenzmessung. Zeitschrift für Berufs- und Wirtschaftspädagogik, 107, 128-137

Winther, E. \& Achtenhagen, F. (2009). Measurement of vocational competencies - a contribution to an international large-scale assessment on vocational education and training. Empirical Research in Vocational Education and Training, 1, 85-108

Wu, M. L., Adams, R. J., Wilson, M. et al. (2007). ACER CONQUEST. Version 2.0. Camberwell: ACER Press

Zhang, Z. \& Lu, J. (2011). Quantitative Structural Representations of Cognitive Tasks for Both Learning and Assessment in Complex Cognitive Environments. Paper presented at the Annual AERA Meeting at New Orleans 